\title{
Case Study of the Actual Application of a Regional Innovation Model Focusing on Gamcheon Culture Village
}

\author{
Na-Rang Kim $^{1}$ and Soon-Goo Hong ${ }^{2 *}$ \\ ${ }^{1}$ Business Research Center, Dong-A University, Busan, Korea \\ ${ }^{2 *}$ Department of Management Information Systems, Dong-A University, \\ Busan, Korea \\ ${ }^{1}$ whitecoral@hanmail.net, ${ }^{2 *}$ shong@dau.ac.kr
}

\begin{abstract}
Gamcheon Culture Village, a well-known tourist area that was regenerated as part of an urban village regeneration initiative, is located in Busan, South Korea. In recent times, the village has received increasing attention as a regional tourism-based regeneration model. However, it is now losing its uniqueness, as a number of similar domestic and international models have mimicked its design due to its success. In addition, as a result of a drastic increase in tourists, problems are arising, such as environmental issues and inconvenience for residents. This study attempts to propose a policy for the sustainable vitalization of Gamcheon Culture Village as a tourist destination based on the application of a co-creation-based regional innovation model, as suggested by Hong et al. (2017). For this purpose, we co-hosted a regional innovation workshop in conjunction with the residents' committee of Gamcheon Culture Village. According to the analysis results, the main obstacles identified in terms of vitalization were as follows: lack of differentiated tangible and intangible content and service; lack of tourist information; traffic problems; and other inconveniences arising from the coexistence of a tourist location and a residential area. A number of solutions were proposed to these problems, including the development of IT-based content and information; the introduction of products and services highlighting the unique color of the region; improvements to the environment; and the development of policy for the residents. This study has contributed, in that it has applied a co-creation-based regional innovation model to the Gamcheon Culture Village for the first time, and it also offers a guideline for solving problems and drafting realistic policy data.
\end{abstract}

Keywords: Co-Creation-Based Regional Innovation Model, IT Platform, Co-Creation, Regional Innovation, Policy, Gamcheon Culture Village

\section{Introduction}

Gamcheon Culture Village is a representative regional tourist spot that was identified for regeneration and has received considerable domestic and international attention in recent times. However, despite the fact that the village has been allocated major budgetary funding of over 10 billion KRW since 2009 for esthetic environmental improvements, the installation of artwork, and the creation of wall paintings, various problems are starting to appear, including lack of events that tourists can experience directly as opposed to on a screen, inconvenience for tourists due to lack of road signs and signposts, and traffic in the area, coupled with environmental problems as a result of the drastic increase in the number of tourists. In terms of external factors, the number of

\footnotetext{
* Corresponding Author
} 
urban villages regenerated has now reached saturation point. These include 82 dilapidated villages[1] that were chosen for the village art project initiated by the Korean government as part of the New Deal art policy during the period from 2009 to 2015. These villages are flooded with art pieces, including walls and street staircases that have been transformed to art works. Tourist destinations have their own unique lifecycle, and typically, this calls for a transition of stages after a certain amount of time [2]. If no effort is made to differentiate a tourist region from other regions, it may enter the phase of decline earlier than expected. This is why regional innovation policy is necessary in the case of Gamcheon Culture Village.

In some cases, the unique strength of the region is sufficient for regional innovation or regeneration to take place, and no special effort needs to be made. However, success in this regard can often be attributed to local residents' strong will to overcome adversity and deal with any problems that may arise. Hence, the participation and collaboration of each agent in the region is critical for regional innovation. In today's world, innovation through co-creation is increasingly under the spotlight. In essence, it involves a diverse range of people creating new value in a region based on participation and collaboration for the purpose of solving a variety of problems encountered by local businesses and society. In a related study, Hong et al. (2017) [3] proposed a co-creation-based regional innovation model where diverse interested parties could develop policy and implement it together based on participation and collaboration. This study attempts to apply such a cocreation-based regional innovation model to the actual problem of tourism vitalization in Gamcheon Culture Village, which is one of the tourist spots that came into being in South Korea after a regional village was regenerated.

\section{Co-creation-based Regional Innovation Model}

Co-creation is a concept that emphasizes communication and collaboration in an environment in which all the participants, including the government, organizations, schools, and citizens, transcend boundaries to communicate and collaborate with each other in order to derive new ideas and create new value in an area. Hong et al. (2017) [3] developed a co-creation-based regional innovation model that had its basis in participation by many interested parties. Specifically, they proposed a stage-by-stage implementation procedure. Figure 1 shows the stages of the implementation, from identifying the agenda in Stage 1 to evaluation and feedback in Stage 7. 


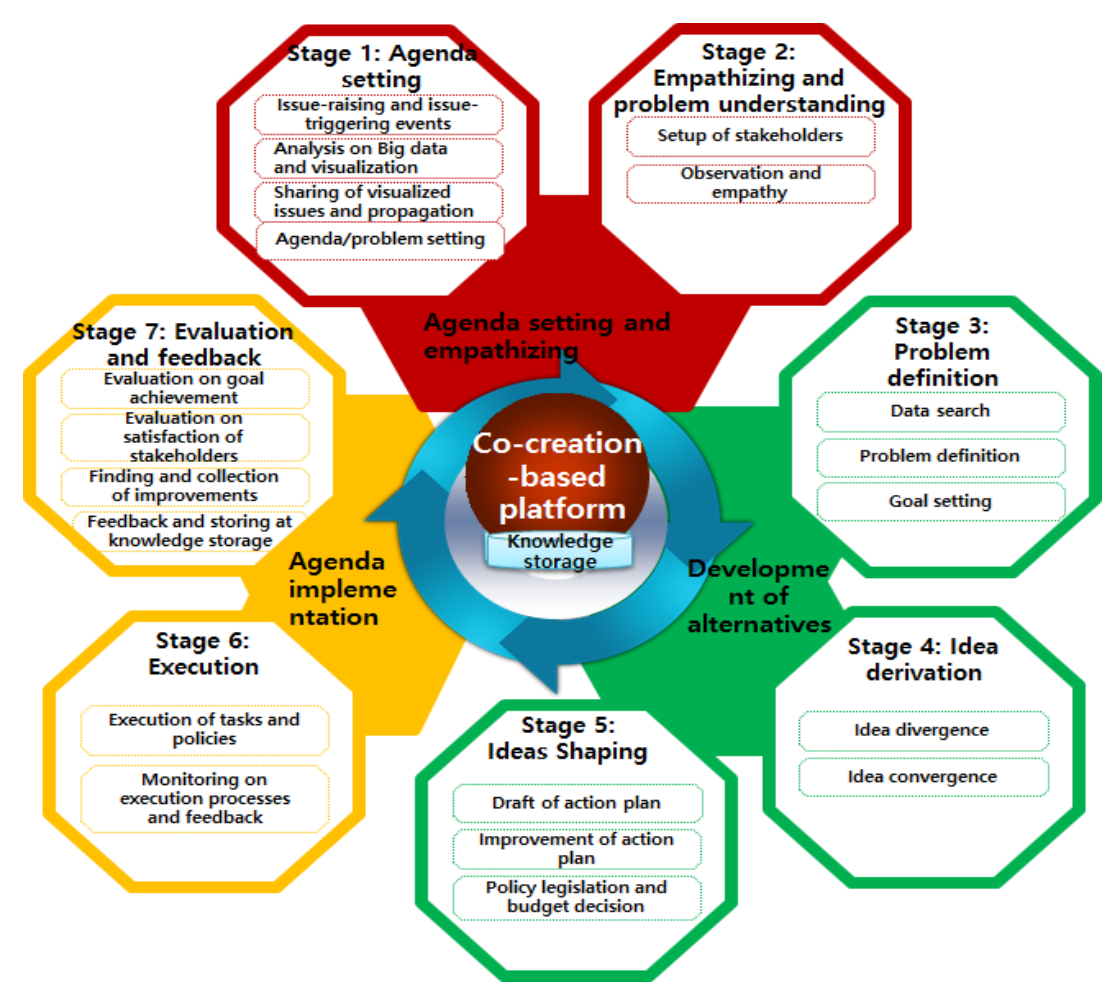

Figure 1. Co-Creation-Based Regional Innovation Model

\section{Application of a Regional Co-creation-based Innovation Model in An Actual Case}

Following the success of Gamcheon Culture Village, a flood of similar culture villages was born throughout Korea. In effect, this led to an urgent need to readdress differentiation strategies and tourism policies for Gamcheon Culture Village, and our application of the co-creation-based regional innovation model is an attempt to do this. We aimed to predict the process of transitioning in order to circumvent the threat of decline and to continuously maintain the potential power of the village as a tourist spot. For this purpose, we applied the necessary processes in seven stages, from agenda setting in Stage 1 to evaluation of goal achievement in Stage 7, and then conducted a case study. In conjunction with the residents' committee of Gamcheon Culture Village, we hosted a regional innovation workshop covering Stages 2 to 5, and a total of 18 parties with an interest in Gamcheon Culture Village participated, including residents, experts in design thinking, experts in regional regeneration, tourists, and representatives of local colleges and companies.

\subsection{Agenda-setting Stage}

Stage 1, Agenda-setting, involves identifying the problems that need to be resolved by analyzing emerging social problems or big data. At this stage, specific tasks are derived through a visualization of the problems under investigation. A tourist spot refers to a region people visit to leave the stresses of their daily lives behind and to satisfy their desire to travel. Meanwhile, tourist spots are also a living or working space, and a resting place for those who reside there. Butler (1980) [4] proposed a theory on the lifecycle of a tourist spot, whereby the number of tourists takes the shape of an S-curve. Specifically, he derived a six-stage hypothesis based on the notion that tourist spots progress through six stages as time passes, namely, the exploration stage, the intervention stage, the growth stage, the settlement stage, the stagnant stage, and last, the decline or regeneration stage. 
Thanks to urban regeneration policies based on differentiated regional characteristics, the number of tourists in Gamcheon Culture Village gradually increased from 25,000 in 2011 to 98,348 in 2012, and then showed an explosive increase to in excess of 1.5 million in 2016 [5]. In the lifecycle typical of tourist spots, the region is currently in the growth stage. However, through an analysis of articles about Gamcheon Culture Village and of trends on portal websites, this study detected an increase in tourist dissatisfaction and a decrease of internet searches for the region. For this reason, we identified investigation of tourism policy in Gamcheon Culture Village as an agenda item.

\subsection{The Empathizing and Problem-Understanding Stage}

In Stage 2, the empathizing and problem-understanding stage, the various interested parties and their reactions to the agenda/problem are observed, and empathy is shown to them. Through an analysis of the interested parties, this study allowed local residents linked with Gamcheon Culture Village, the residents' committee, tourists, companies, and experts in urban regeneration with an interest in Gamcheon Culture Village, to participate in the application of the case. Our research team contacted the relevant interested parties, including ward officials and local committee members, multiple times and then co-hosted a workshop with the residents' committee, in which a total of 18 participants were divided into three teams. The workshop took place from 9 am to $7 \mathrm{pm}$ on October 8th 2016. Prior to the workshop, we guided the participants to enable them to obtain background knowledge on Gamcheon Culture Village and to observe it. In the empathizing stage, we listened to a lecture on the history of Gamcheon Culture Village and its current development delivered by an expert in regional regeneration, who had also spent his childhood in the village. Afterwards, we chose interview themes from the observation methods in order to listen to the voices of the diverse interested parties and to collect information.

\subsection{Problem Definition Stage}

In Stage 3, the problem definition stage, the agenda/problem determined was defined in a more specific way through an exploration of the existing main data, and the final goal was based on these redefined contents. In this study, the following problems were defined based on the insights identified in the empathizing stage during the design-thinking workshop. The first team pointed out some of the obstacles to revitalization of the village, as follows: lack of content for tourists that is exclusive to Gamcheon Culture Village; unexpectedly difficult access to the village; and problems obtaining information about Gamcheon Culture Village. Of the above issues, the team identified the main problem as the need to target people in their twenties, who make up the majority of the tourists that visit Gamcheon Culture Village:"Registration of official account in social network service (SNS) of Gamcheon Culture Village is necessary, as information on Gamcheon Culture Village is currently very limited."

The second team pointed out a number of other issues hindering tourism, as follows: a concentration of tourists in a particular time slot; lack of goods highlighting the unique characteristics of Gamcheon Culture Village; traffic problems; lack of real-time information; and inconvenience due to the ambiguous distinction between the village as a residential area and as a tourist spot. Specifically, the team defined the problem as follows: "Products that have the unique color of Gamcheon Culture Village are necessary to offer tourists a memorable travel experience."

The third team pointed out other factors blocking tourism development in the area, for example, the lack of tourist content, a complex and barely legible map, exaggerated promotion, reckless village development, and environmental problems. In particular, the team noted that "content and events are required that can enhance visitors' satisfaction 
with the service."

\subsection{Idea-derivation Stage}

Stage 4, the idea-derivation stage, was aimed at extracting as many ideas as possible, including new initiatives, through ideas given by the diverse interested parties. Among the idea release schemes available, this study used brainstorming and reverse brainstorming to solve the problems defined in Stage 3. The first team prioritized the following initiatives: near-field communication (NFC) tours; a history museum on the street; specialty goods made in Gamcheon; inviting performance groups to put on shows in vacant houses; more murals; opening a one-day academy; opening diverse eateries; game making based on augmented reality; and registering an official account of SNS for Gamcheon Culture Village. Based on an evaluation using feasibility and effectiveness as a standard, "promotion through SNS and map and game making by using augmented reality" was selected. The second team proposed rubber shoe manufacturing that would be unique to Gamcheon Culture Village, taking account of the fact that there are shoes factories, as well as a traditional flower shoe manufacturer, in Gamcheon Culture Village already, and that many residents who worked in the shoe and clothes manufacturing industry in the past still live in the region. The team proposed the idea of selecting fish as the mascot to represent Gamcheon Culture Village and making souvenirs featuring fishthemed accessories.

The third team proposed the development of content aimed at considering the unique color and environment of the region, including giving away stamps and offering prizes by drawing lots; a paid mural painting competition; gifts for visitors with photos previously taken in a given photo zone; and a ginseng-digging trip to the mountain.

\subsection{Idea-shaping}

In Stage 5, the idea-shaping stage, which corresponds to the prototype application stage of design thinking, the final draft is determined through the shaping of ideas that are then piloted and improved based on the interested parties' opinions prior to budget implementation. In this study, ideas were shaped through a storyboard, a schedule plan, and role play. A development plan for the creation of online and offline content exclusive to Gamcheon Culture Village was determined and modified over the course of demonstrating and testing the draft, and many interested parties and experts participated in opinion exchanges and voting.

\subsection{Summary of how the Case is Applied}

The co-creation-based regional innovation model by Hong et al. (2017) [3]consists of a total of seven stages, as follows: Stage 1 - agenda finding; Stage 2 - empathizing and understanding the problem; Stage 3 - problem definition; Stage 4 - idea derivation; and Stage 5 - idea shaping. All of these stages were applied to the case of Gamcheon Culture Village. Stages 6 and 7 are not included in the coverage of this study, however, as they involve implementation and feedback, which are not part of the project scope. In particular, observation and empathizing, problem definition, idea derivation, and idea shaping were achieved based on a design thinking workshop. Table 1 shows a summary of how the regional innovation model can be applied to the case of Gamcheon Culture Village. 


\section{Table 1. Application of the Regional Innovation Model to the Case of Gamcheon Culture Village}

\begin{tabular}{|c|c|c|}
\hline Stage & Substage & Example of application in Gamcheon Culture Village \\
\hline \multirow[t]{2}{*}{ Agenda setting } & $\begin{array}{cr}\text { Issues } & \text { raised and } \\
\text { issues } & \text { triggering } \\
\text { events }\end{array}$ & $\begin{array}{l}\text { - initiation of policy issue- decrease in search-based tourist } \\
\text { inflow was detected while monitoring tourist trends in } \\
\text { Gamcheon Culture Village } \\
\text { - increase in tourist dissatisfaction } \\
\text { - too many urban regeneration villages in the wider context }\end{array}$ \\
\hline & $\begin{array}{l}\text { Agenda/problem } \\
\text { setting }\end{array}$ & - check tourism policy in Gamcheon Culture Village \\
\hline \multirow{3}{*}{$\begin{array}{l}\text { Stage } 2 \\
\text { Empathizing } \\
\text { And } \\
\text { Problem } \\
\text { Understanding }\end{array}$} & $\begin{array}{ll}\text { Setup } & \text { of } \\
\text { stakeholders }\end{array}$ & $\begin{array}{l}\text { - determine interested parties relating to Gamcheon Culture } \\
\text { Village }\end{array}$ \\
\hline & & $\begin{array}{l}\text { - parties interested in Gamcheon Culture Village, including the } \\
\text { planning group of the creative city in Saha-gu, Busan City, local } \\
\text { residents and artists, local colleges, local merchants, the } \\
\text { residents' committee of Gamcheon Culture Village, tourists, and } \\
\text { local companies }\end{array}$ \\
\hline & $\begin{array}{l}\text { Observation } \\
\text { empathy }\end{array}$ & $\begin{array}{l}\text { - listening to the opinions of interested parties and observing } \\
\text { them to understand their emotions, thoughts, and attitudes } \\
\text { through indirect experience and cognitive checking } \\
\text { - direct observation of and interviews with the interested } \\
\text { parties, including residents and tourists in Gamcheon Culture } \\
\text { Village } \\
\text { - design-thinking workshop } \\
\text { - identifying obstacles to tourism vitalization in Gamcheon } \\
\text { Culture Village through the empathizing stage of design } \\
\text { thinking }\end{array}$ \\
\hline Stage 3 & Data search & $\begin{array}{l}\text { - searching for other cases of regional regeneration for tourism } \\
\text { purposes }\end{array}$ \\
\hline \multirow{2}{*}{$\begin{array}{l}\text { Problem } \\
\text { Definition }\end{array}$} & Problem definition & - problem definition through design-thinking workshop \\
\hline & Goal setting & $\begin{array}{l}\text { - maintaining tourism vitalization in Gamcheon Culture } \\
\text { Village }\end{array}$ \\
\hline \multirow{2}{*}{$\begin{array}{l}\text { Stage } 4 \\
\text { Idea } \\
\text { Derivation }\end{array}$} & Idea divergence & $\begin{array}{l}\text { - idea release in design-thinking workshop (brainstorming and } \\
\text { reverse brainstorming) }\end{array}$ \\
\hline & Idea convergence & $\begin{array}{l}\text { - Selecting ideas from the proposed ideas by evaluating their } \\
\text { feasibility and effectiveness }\end{array}$ \\
\hline \multirow{2}{*}{$\begin{array}{l}\text { Stage } 5 \\
\text { Ideas Shaping }\end{array}$} & Draft of action plan & $\begin{array}{l}\text { - development of a draft for each idea using a storyboard, } \\
\text { schedule plan, and role play }\end{array}$ \\
\hline & $\begin{array}{l}\text { Improvement } \\
\text { action plan }\end{array}$ & $\begin{array}{l}\text { - over the course of the demonstration and test process of the } \\
\text { drafts, residents and experts participate in opinion exchange and } \\
\text { vote to determine unique online and offline content } \\
\text { development exclusive to Gamcheon Culture Village, and how } \\
\text { to improve that content }\end{array}$ \\
\hline
\end{tabular}

\section{Conclusion}

This study attempted to address the problem of tourism vitalization in Gamcheon Culture Village, which is a representative case of regional regeneration in Busan, and is experiencing increasing domestic and international focus as a tourist spot. To this end, we applied the methodology of a co-creation-based regional innovation model, whereby diverse interested parties collaborated to solve the problems identified. The application of the co-creation-based regional innovation model to tourism vitalization in Gamcheon Culture Village produced several positive outcomes. First, we could get closer to the real problems through the empathizing stage, and we used many of the resulting ideas for policy making, as this approach enabled diverse interested parties to engage in a liberal and intensive debate over a short period of time. We were also able to increase the level of overall understanding and policy interest regarding Gamcheon Culture Village, and 
this will enhance the probability of success in executing policy in the area. In addition, we were able to create a space for debating sustainable tourism vitalization in Gamcheon Culture Village. Meanwhile, the residents' committee was concerned about the distrust and conflict among the residents caused by policy defined by a small number of its members. By resolving these conflicts, we managed to achieve sustained participation by the residents. Second, the co-creation-based regional innovation model offered a guideline on successful policy amendment for the relevant interested parties, arising from existing policy development. In particular, Gamcheon Culture Village is currently in the growth stage of the tourist area lifecycle, and is experiencing an explosive increase in domestic and international tourists. However, Gamcheon Culture Village is losing its comparative uniqueness, as many similar domestic and international models appeared after its successful regional regeneration as a tourist spot. Moreover, the village is likely to transition to the decline phase soon, as many problems have emerged following the drastic increase in tourists, including environmental problems and other inconveniences for both tourists and residents. This study has provided a chance for successful execution of policy to achieve sustainable regional regeneration-focused tourism vitalization through application of a co-creation-based regional innovation model.

Meanwhile, some shortcomings came to light when the model was being applied in this case. First, users had difficulties applying the model due to its complexity. Second, we were unable to collect diverse information in the empathizing stage as it was hard to meet interested parties in the actual field. Participation by the relevant experts and interested parties was essential for most of the stages, such as the opinions and evaluations of experts at the evaluation stage after idea release. In addition, a database on the relevant human resources became necessary in the course of the research. Third, applying this model offline requires too many tangible and intangible resources, including time and money. We felt there was a necessity to develop schemes that could be applied more easily and promptly using IT, for example, an IT-based online platform. The current study has an academic basis in that it applies a regional innovation model to the case of Gamcheon Culture Village, and this may lead to other studies on this area in the future. In terms of its practical contribution, the study can be used as a guideline for problem solving in its provision of specific procedures and methods that can be applied in administrative organizations and professional institutions when they need to evaluate the development, maintenance, or improvement of policies when policy issues occur. The study also provided realistic policy data, as it facilitated the collection of opinions from diverse interested parties through its application in the case of Gamcheon Culture Village. However, the study had time limitations at the improvement stage due to the short duration of the workshop. Further studies are required that can investigate the implementation of the ideas derived in the study, as well as provide feedback on the process in the future.

\section{Acknowledgments}

This work was supported by the Ministry of Education of the Republic of Korea and the National Research Foundation of Korea (NRF-2015S1A3A2046781). 


\section{References}

[1] Newswise, If you want to transform into a transformed city, like the Busan Gamcheon Culture Village, (2016).

[2] E. Y. Chang, "A Study on the Extension of the Life Cycle of the Tourist Places", Doctoral thesis, Gyeong-Gi University, (2000).

[3] S. G. Hong and N. R. Kim, "Designing an Innovative Model for the Co-Creation - Completion of Innovation through IT and Design Thinking", Yu Won-books, Seoul, (2017).

[4] R. W. Butler, "The concept of a tourist area cycle of evolution: Implications for management of resources", Canadian Geographer, vol. 24, no. 1, (1980), pp. 5-12.

[5] KBS, Water colorized city 'Gamcheon Culture Village', (2016). 